\title{
How to Understand Custodial Belonging
}

AnN GAME, Demelza MARLIN AND

ANDREW METCALFE

UNIVERSITY OF NEW SOUTH WALES

Debates about ecological responsibility are interested in different forms of belonging. This article develops an understanding of a custodial form of belonging based on the logic of relation, as distinct from a proprietorial form of belonging based on the logic of identity. Theorists working on questions of belonging use a language of custodianship when describing a sense of responsibility and care that arises through connection or relation. We argue, however, that the full significance of custodial belonging cannot be appreciated when theorists derive their understanding of connection from within the terms of identity logic. In other words, when belonging is understood in terms of identity and identification, custodianship is inadvertently reduced to a proprietorial form of responsibility and care.

We begin by giving an account of the differences between identity and relational logics, drawing out the implications for understanding different forms of belonging. While social theory commonly understands relation or connection as the interaction of definable identities or subjects, we show that relationality is an 
ontological state of non-finitude that cannot be reduced to identity and which is instead the primal ontological state from which identity emerges. While identitybased theory, then, cannot account for relation, we show that relational theory recognises the co-existence of and relation between identity and relational states. We will outline a relational approach that, by distinguishing different forms of being, space and time, allows for conceptual distinctions between different forms of sociality and, hence, belonging.

We then address Australian research on custodial belonging. Focusing on the influential work of Deborah Bird Rose, we argue that there are tensions between, on the one hand, her attempts to recognise connected forms of belonging, and, on the other, her conceptual reliance on the assumptions of identity logic. Our primary concern here is to indicate relational possibilities in her work precluded by the language of identity. In particular, we suggest that the concept of ecological being allows for a specificity and inclusiveness that are not recognised by Rose's concept of the 'ecologically emplaced self'.

\section{- IDENTITY AND RELATIONAL LOGICS}

In this section we outline a relational approach, drawing on the work of Martin Buber. ${ }^{1}$ Buber provides the most rigorous account of relational logic as he shows how it allows for the inclusion of both identity and relational logics and the relation between them. We will start with Buber's distinction between 'I-It' and 'I-Thou', each of which is characterised by a distinctive ontology, space and time.

The ontology of I-It is that of an identity or subject, a form of being that is finite and bounded, a thing, defined by a border between self and other, subject and object. In other words, subjecthood is based on the logic of binary oppositions; the identity of an 'I', one and self-same, is constituted through and (implicitly) depends upon a 'not-I'. The other, it follows, is only seen from the perspective of the self and not respected for their otherness; that is, identity logic reduces difference to opposition (the other is simply 'not-I'). As this logic of opposition implies, the ontology of identity presumes that space is Euclidean, that entities are defined by a non-shared location or position on a grid. Positions are distinguished by distance understood as a spatial void, a separation without connection, an opposition 
between inside and outside, subject and world. Since these distances are measurable (a metre, a kilometre), Euclidean space is abstract and homogenous.

The temporal counterpart to Euclidean space is linear time, time on a line of distinct units, past, present and future. Like Euclidean space, linear time is an abstraction from lived experience; it is homogeneous, understood as a temporal series, measurable in minutes, hours, days. This time is characterised by both an endless repetition of the same and a forward moving trajectory; the present is no more than an impossibly small measure of time, overwhelmed by the anticipation of the future or nostalgia for a future past.

Within the world of I-It, relation is logically secondary, arising from the coming together of previously separate things. But, Buber says, this world of bounded things is not the only world. He says:

The life of human beings is not passed in the sphere of transitive verbs alone. It does not exist in virtue of activities alone which have some thing for their object.

I perceive something. I am sensible of something ... This and the like together establish the realm of $I t$.

But the realm of the Thou has a different basis.

When Thou is spoken, the speaker has no thing for his object ... Thou has no bounds ...

The relation to the Thou is direct. No system of ideas, no foreknowledge, and no fancy intervene between $I$ and Thou ... No aim, no lust, and no anticipation intervene between $I$ and Thou.... ${ }^{2}$

The relational being of I-Thou is not the being of identity or subjecthood. Not a one or thing generated by the exclusion of or opposition to another one or thing, relational being is non-finite or dialogic, based, this is to say, on the non-arithmetic principle of no-thing-ness. When used as a synonym for infinitude, nothingness is not lack but the inherent openness or potential of relational being. In this world, difference is not experienced as the simple opposite of sameness. Neither inside, nor outside, the world of relation is characterised by a difference and sameness that cannot be located or defined against any other thing. To make sense of this principle of different-and-same, it is necessary to appreciate the particular quality of relational space and time. 
While locations of identity occur in the abstractions of Euclidean space and linear time, relations happen in the uniqueness of here, now. Indeed, the nonlocatable here, now is the living reality from which the Euclidean and the linear are abstractions: 'With all deference to the world continuum of space and time I know as a living truth only concrete world reality ... Inseparable, incomparable, irreducible, now, happening once only, it gazes upon me with an awesome look'. ${ }^{3}$ The nonEuclidean here of I-Thou cannot be mapped because there is no delimitation of what is here; this is not the here of a bounded identity or subject, but the here of connection from which there are no exclusions. In the dialogic of I-Thou, 'here' and 'there' are not separate locations; here-and-there is an ecological space in which insides and outsides are intertwined, in which the inside is also outside, and the outside is inside. ${ }^{4}$ The term ecological is important here, for, in this space, relations take the form of mutual participation; that is, of being in the world and the world in being. Ecological space is a space without locations and it is only this space that allows for difference-and-sameness.

Just as the non-Euclidean here is here-and-there, so the non-linear now is nowand-then, an unfolding present that holds within it all time, past, present and future. For Buber, the present only comes with the relation of I-Thou: 'the real, filled present, exists only in so far as actual presentness, meeting and relation exist. The present arises only in virtue of the fact that the Thou becomes present'.5 Connectedness always occurs in this present, which 'is not fugitive and transient, but continually present and enduring'. 6 '[C]reation', Buber says, 'does not merely take place once in the beginning but also at every moment throughout the whole of time'. ${ }^{7}$ In short, 'the beginning' is always with us, the unique, non-linear now.

To illustrate Buber's distinction between I-It and I-Thou, we will consider his example of the different ways of encountering a tree. When he is in an I-It form of being, a subject in a world of objects, Buber says he can see a tree as picturesque, he can admire its vitality, he can classify it as a species and study it as a type, he can see it as an example of a scientific law or turn it into a number. But, in all these cases 'the tree remains my object, occupies space and time'. ${ }^{8}$ Reified, the tree, like the subject, is locatable in Euclidean space and linear time. This is the representational categorised world of identities. But it is not the only world. 
It can, however, also come about, if I have both will and grace, that in considering the tree I become bound up in relation to it ...

To effect this it is not necessary for me to give up any of the ways in which I consider the tree. There is nothing from which I would have to turn my eyes away in order to see, and no knowledge that I would have to forget. Rather is everything, picture and movement, species and type, law and number, indivisibly united in this event.

Everything belonging to the tree is in this: its form and structure, its colours and chemical composition, its intercourse with the elements and the stars are all present in a single whole. ${ }^{9}$

The significance of being 'in relation' with the tree hinges on the preposition in, which can be used in either a Euclidean or a wholistic, ecological sense. In the former sense, in implies containment: there are insides and outsides demarcated by walls. Just as chalk is in a box, the tree is in the categories and spatial boundaries that define it. But in the wholistic or ecological sense, in implies participation and implication. When we are in life, or in the world, we are in a relation that does not locate insides or outsides or identities. There is just this, whatever is present, here, now. The tree is not there, at a distance from my here; all there is is here, here-andthere, a presence that involves both me and the tree, which 'have to do with each other', which are not the same but are nonetheless in each other. The inclusive nature of this particular encounter is indicated by Buber's reference to the nonfinite, wholistic quality of I-Thou: 'its intercourse with the elements and the stars are all present in a single whole'. Thus, we could say, for example, that all trees (and birds and elements and places) are present in this tree: the particular holds and opens to the whole.

We began this article by making a distinction between a form of belonging based on identity and one based on relation. In the light of this discussion of Buber's I-It and I-Thou, we can now clarify the distinction between different forms of belonging. When based on identity, belonging arises through an identification with, for example, a place, thus presuming a sense of sameness and an exclusion of otherness and difference. This identity-based understanding of belonging informs theories of community and belonging that emphasises attachment, mutual interests and a shared-sense of 'who we are'.10 
Freya Mathews, for instance, argues that a sense of belonging arises when people are able to see themselves in place and to see place in themselves; that is, when they recognise place as continuous with the self.11 In her account, the identification of self with place forms the basis of community. 'When I assume the name Freya of Brunswick or identify as Merri Creek woman, then I feel an immediate affinity with others whose names or identities link them to my place'.12 In Mathews' account, communities form around shared interests and, she argues, these shared interests neutralise initial differences between people, creating a common identity around their relationship to place. For Mathews, then, belonging is the achievement of a sense of sameness that cannot acknowledge difference.

Many contemporary social theorists have been critical of the concepts of belonging and community for this reason, arguing that they are predicated on a desire for unity, and are unable to acknowledge difference. ${ }^{13}$ While proprietorial forms of belonging are exclusive, privileging sameness over difference, Buber's IThou relation shows us that there is another form of belonging which is inclusive, involving a meeting with difference in which sameness and difference are intertwined. This is custodial belonging. It is a form of belonging based on care and mutual participation.

The concept of custodial belonging will be developed more fully in the following section, but we would like to make some clarifying remarks at this juncture. In recent years the language of custodianship has become a central feature of accounts of belonging in Australia. Situated in the broader question of how settler cultures can belong in Australia, a number of theorists have turned to Indigenous communities to develop alternatives to models of belonging based on ownership and possession. Theorists such as Moreton-Robinson, Plumwood, Rose and Mathews write about an 'ontological' relationship to place which is based on mutual responsibility: place sustains the life of those who live in it and, in turn, the people and other life forms that live on the land take care of it.14 For some, the responsibility that underlies such an ontological relationship requires an acceptance of difference. 15 However, many theorists still presume that responsible action is the action of a subject for an object (a place, community or another person) and thus they retain the analytical privilege of identity within the relationship between persons and places. This logic sets the other (whether it is a person or place) at a 
distance which then needs to be overcome. Returning to the example above, in the case of Mathews' understanding of belonging, it is an initial and oppositional form of difference that is overcome by the establishment of shared interests and common goals.

Again Buber can help us here. He argues that I-Thou is the basis of responsibility because to be responsible is to respond: 'Genuine responsibility exists only where there is real responding'. ${ }^{16}$ Where there is a subject who assumes responsibility for an other, there can be no real responding, for 'the tree remains $m y$ object'. ${ }^{17}$ A response to otherness or difference only arises through being 'bound up in relation' with the tree, so that the tree is not a thing but a living presence that is at once different and connected. In relation, call and response cannot be located in Euclidean space and linear time, and so responsibility cannot be experienced as the possession of any one or thing: the difference that calls-and-responds is here-andthere, occurring in the real lived present. 18

—Deborah BiRd Rose and 'the emplaced ecological selF'

We will now consider the work of Deborah Bird Rose, a leading scholar in the field of the ecological humanities in Australia. Drawing on her anthropological fieldwork among the Yarralin people, Rose has developed an understanding of belonging based on ecological interdependence, through which the well-being of persons is tied to the well-being of places. An 'emplaced ecological self' cares and is responsible for the place that cares for them. ${ }^{19}$

In 'An Indigenous Philosophical Ecology: Situating the Human' Rose describes the relationship between persons and place as one of mutual benefit.20 Mutual benefits are exchanges between species which connect the interests of humans to the interests of non-humans and the environment. An example of mutual benefit given by Rose involves sustainable forms of hunting and gathering which foster life for both humans and other species, as well as the land. She notes that the Aboriginal burning of country removes long grasses and grass seeds and encourages new growth that is rich in nutrients. While this provides an excellent food source for wallabies, kangaroos, turkeys and cockatoos, it also benefits humans because it enables them to better see animal tracks and because the fattened animals are better to hunt. ${ }^{21}$ Exchanges of benefit between species provide the human with an 
'expanded sense of self brought about by various consubstantialities' with the places to which they belong. ${ }^{22}$

Rose develops this 'expanded sense of self' when referring to the flows of information that bridge differences between individuals, groups and species, giving them access to regions they wouldn't otherwise inhabit. ${ }^{23}$ She gives an example of a swift, flying across the sky, which gives humans access to valuable information about the seasons: when the swift flies low it tells that the wet season is about to begin, and when it flies high it tells that winter is imminent and that humans should make camp. The swift, in other words, gives humans knowledge of what is happening in the upper atmosphere, emplacing humans within this enlarged domain.

Rose describes the resulting relationship to place in custodial terms. She speaks of an ecological self that 'sustains the country in the self and the self in the country'. ${ }^{24}$ An ecological self is engaged in dialogue with place. She gives an example of Jessie Wirrpa:

Jessie took care of her country and her country took care of her ... Country was the ground of her being; she was a walking and ephemeral nexus of country, Dreamings, and care. Nothing stood alone in Jessie's country; everything was happening because of the care of others ... An Aboriginal ethic of ecological engagement requires that subjects, human and nonhuman, attend to each other ... Jessie Wirrpa lived an ethic of intersubjective attention in a sentient world where life happens because living things take notice ... [T] his ethic is not human-centred. Care of one's country, one's people, one's Dreaming sites, and one's non-human countrymen are not governed by different ethics; they are actions through which people bring forth, and are themselves brought forth by, interacting subjectivities. $^{25}$

Through this ethic, Rose aims to provide an alternative to the paradigms of mainstream Western science and philosophy which separate the human from the world ${ }^{26}$ and view the nonhuman world as a mere backdrop for human projections and intentions. ${ }^{27}$ Rather than the non-human world being comprised of objects, it has the quality of being a subject: 
[I]n this Indigenous system, subjectivity in the form of sentience and agency is not solely a human prerogative but is located throughout other species and perhaps throughout country itself. Subject-subject encounter is an ecological process that undermines the whole basis of hegemonic anthropocentrism. ${ }^{28}$

As Rose makes clear, human and non-human alike are subjects, each separate and distinct, whose interactions bring about intersubjectivity.

Rose is insistent on the importance of specificity in these interactions. She says: 'Mutual care is neither infinitely obligatory, nor is it diffuse and undifferentiated. The structure of mutual care is local and bounded'. 29

[G]eneralizability ... contrasts forcibly with the culture of place that is characteristic of many kin-based societies. From a perspective developed in dialogue with Aboriginal Australian peoples, we would ask questions about specificity: 'which country? which people? ... the genius of Aboriginal Australians finds its greatest expression in a theory and practice of place ... It is evident in the sacred geography of country, sites and tracks, and it is central to the very idea of Dreaming.

Aboriginal people localize social groups within country ...

Consubstantiality with country is not generalized as earth and humanity, but is pre-eminently local ... this country, this group of people, these Dreamings ...

Specificity requires both localization and temporalization. It requires exchanges of substance between specific persons and places. Because exchanges are specific and personalized, they unfold in real time. They are not just waves in the cosmic sea of un-change. ${ }^{30}$

As these passages suggest, Rose understands specificity and thisness to mean location, which is to say identifiability in time and space. Her aim is to distinguish the specific, 'the real here and now of our lives', from what she understands to be the abstractedness and 'generalizability' of 'the archetypal'. ${ }^{31}$ The archetypal, for her, is 'cosmic flux' which abolishes time in 'endless cycles of repetition' which are 'inimical to growth'. ${ }^{32}$

Summing up, Rose's insistence that 'ecological engagement requires that subjects, human and non-human, attend to each other'33 allows her to challenge the 
human-centredness of the proprietorial model of belonging and to propose, instead, a custodial model. And her insistence on the notions of emplacement and specificity highlight the ways in which care and responsibility derive from real life rather than abstract principles. We think, however, that there are conceptual tensions in her work as a result of her presumption of the ubiquity of identity logic. While she seeks to emphasise connection, she usually assumes that it derives from the interaction of subjects, which is to say that connection is secondary to the separation that constitutes subjecthood. Furthermore, when turning non-humans into subjects, she is inadvertently projecting human-centred assumptions about identity and subjectivity. We think that a relational logic might allow Rose to more consistently develop an understanding of ecological responsibility.

\section{-RELATIONAL POSSIBILITIES}

In this section we will draw attention to some of the relational possibilities in Rose's work, using these possibilities to indicate the conceptual tensions involved. Let us take a rich example of ecological intertwinement that Rose experienced during her fieldwork. She describes her participation in the Bandimi ceremony, which involves a dance through which Dreaming power contained within the earth is called up:

I learned to dance, and so I learned to work the ground with my feet, and learned to make the dance-call that is integral to the pattern. Thus I learned that the body connects earth and air when you dance. The call comes from deep within and is propelled by the impact of your feet on the ground. It comes to feel as if the ground itself propels your voice out into the night sky. That call starts somewhere below your feet and ends somewhere out in the world. The call is a motion, a sound, a wave of connection. You are dancing the earth, and the earth is dancing you, and so perhaps you are motion, a sound, a wave of connection. You are bearer of the call, and perhaps you are also bearer of an answer. ${ }^{34}$

Rose's description of her relation with the ground reminds us of Buber's description of becoming bound up in relation with the tree. We imagine that the border that distinguishes the ground from her foot would be intertwined with her body. Although she feels the pressure of the earth beneath her feet and enjoys the abrasive touch of dry dirt meeting soft skin, the ground is not 'there' at a distance. 
Nor is it 'here' in a Euclidean location. This experience occurs in the here of presence, here-and-there. This intertwined logic is implied when Rose says 'You are dancing the earth, and the earth is dancing you, and so perhaps you are motion, a sound, a wave of connection.' And, when she says that the call 'comes from deep within', she suggests that the call does not come from deep within any locatable thing, but, rather, comes from the depth of a relation, from a state of no-thingness or infinitude: 'That call starts somewhere below your feet and ends somewhere out in the world.'

This discussion of space leads to a reconsideration of the question of specificity. The specificity of this dance and this ground is not based on Euclidean-linear location, but only arises through the no-thingness of connection. Because it is not based on location, the specific is inclusive, holding the whole. To paraphrase Buber, the ground's 'intercourse with the elements and the stars are all present in a single whole'. Likewise, each specific footfall reveals anew the whole of the dance, each step feeling just right, without any rush to an end. Furthermore it is the unbounded quality of specificity that allows this dance, now, to be an experience of the presence of the generations of dancing, the presence of Dreaming. This now holds within it all time.

Rose's description of the experience of Bandimi dancing suggests a relational ontology. There is no clear or definitive demarcation between earth, sky and body. Each is bound to all the others; different but inseparable elements of her experience. Nor is it possible to identify the source from which the dance derives, because the energy of the dance seems to come from everywhere. Rose describes this energy as a 'call' or 'wave of connection', shared by all participants, and makes the important point that you are both the bearer of the call and the bearer of the response. What this points to is a form of being that is non-finite, that involves the intertwining of insides and outsides. Accordingly there is no process of moving between finite points (earth, sky, body, caller and responder) for they are already implicated in each other. Indeed, we imagine that rather than having the restlessness of continuous movement, the dance would have a feeling of movement-and-stillness.

While Rose's description of the experience of dancing raises for us the possibility of a relational analysis, her own analysis of it relies on locations, linear time and the actions of subjects. She uses the idea of people flipping between subject 
positions, from 'agent' to 'vehicle' to 'agent'. This is a logic that derives 'mutuality' from the oppositional logic of separate positions: for her it is not possible to be both agent and vehicle simultaneously; one can only take turns in being agent or vehicle.

For the dancer there is also one's embodied iridescence. There is the flip between the feet on the ground and the ground on the feet: who is the dancer and who is the danced? If I hold the analytic privilege on motion, I find that both are dancer and danced, and that the significance of this mutuality is located in the flip back and forth between us ...

One is transformed from agent (calling) to vehicle (being called or moved through) and back and forth all night long. To dance, therefore, is to move within a generative, liminal matrix of betweens-between the caller and the respondent, between the ground and the foot, the earth and the air; between the many interlocking patterns and flips, and between the enduring and the ephemeral. 35

Rose's analysis hinges on the notion of a between that joins separate locations or identities, 'caller' and 'respondent', 'ground' and 'foot'. In this model connections are secondary to the separations they attempt to bridge. The logic of oscillation implies a similar sense of separation in time. Rose's reference to something flipping back and forth between the dancer and the danced evokes a sense of taking-turns: now it is the dancer that embodies the energy, now it is the dance. Another way of saying this is that oscillation is sequential, events taking place in points in time which are logically and experientially distinct. This linearity cannot comprehend an experience of simultaneity, for example, an experience of being caller-andrespondent at the same moment. When Rose emphasises motion in order to get from one position to another, she cannot allow for the possibility of an experience of movement-and-stillness in which the destination is nowhere but here.

This is not the only place where Rose discusses temporality. She often uses her anthropological work with the Yarralin people to highlight the inadequacy of western assumptions about linear time. ${ }^{36}$ A clear sense of Rose's understanding of indigenous experiences of time, and the way they confound western concepts of linearity, can be found in her widely cited book Dingo Makes us Human. Rose tells us that the Yarralin people understand events and entities with reference to two distinct categories of time: ordinary time, which can largely be understood in terms 
of western concepts of sequence and linearity, and Dreaming, which cannot. Ordinary time, as she explains, is characterised by sequence and change. Life has a beginning, a middle and an end, and all things grow old and die. ${ }^{37}$ 'Events occur and never recur in the same way.'38 Dreaming, on the other hand, is a bounded period (about a hundred years before the present) in which enduring events take place. ${ }^{39}$ Dreaming is the before time, from which Law emerged.

In rituals, Dreamings are remobilised and brought into the present. For example, Rose says, 'Birth brings Dreaming into the present. Each birth is a microcosmic recapitulation of the origins of the cosmos; each birth regenerates women's Law and being. So, too, does ceremony'.40 Only in this way are people drawn out of the fleeting and ephemeral of ordinary time and into enduring cycles.

Rose tells us that events occurring in ordinary time only become enduring when they are part of 'oscillating cycles' which 'recur'.41 Our problem is that recurrence is a linear concept, implying a repetition of the same. Thus for Rose, the connection of the birth of this child to the births and deaths of ancestors and to Dreaming lives takes the form of repetition. This elides uniqueness and reduces the specific events of people's lives to mere abstractions; they become examples of common structures or cycles. We would argue that the birth of this child is not just new and not just repetition, but is the rebirth of the whole world.

Rose retains identities and locations to emphasise specificity and difference; that is, to avoid reductions to the sameness of abstractions. However, we have seen that it is identities and locations that are governed by the principle of sameness, characterised by abstractions and generalisations. This is the point of Buber's account of an I-It encounter with the tree. The specificity of an encounter only arises within the relational non-finite logic of I-Thou, which suspends identities and allows for incomparability. We think that Rose's description of the dance experience accords with the I-Thou logic, in which this is present and cannot, for that reason, be defined or bounded.

This has implications for understandings of ecological relations and custodial forms of belonging. Let us return to the example of the swift. Rose says that the swift's flight portends the future, giving humans access to regions they don't ordinarily inhabit; she suggests that the swift's flight gives them access to a place that is defined as not here, and a time that is not now. The sky is simply at a distance, 
a distance which information must traverse in order to get to the human standing on the earth below, ready to receive. A relational analysis would, by contrast, put the emphasis on the specificity of here, now. In relational ontology, humans extend their knowledge of country by seeing through and with the swift, by feeling the coming winter through the swift's body. In this state, information doesn't pass between humans and nonhumans; it doesn't get to the human by crossing the vastness of a space which separates human and non-human. Rather, the information carried by the swift would be accessible to the human because, in that moment of connection, human is also swift, also sky, also country. The human would not be one of a multiplicity of beings who occupy space within country. Rather, through relations with the swift and earth and sky, the human is a particular expression of country's being. In other words, the human is an ecological being, human-and-non-human.

This analysis changes the way we might think about Rose's claim that Jessie Wirrpa 'took care of her country and her country took care of her'. ${ }^{42}$ She emphasises the mutual benefit for 'interacting subjectivities'. ${ }^{43}$ A relational approach would say that country and Jessie are intertwined, that Jessie doesn't necessarily oscillate between being an agent and being a vehicle of country, for, in relational states, she is both at once. She is ecological being, Jessie-and-country. In this state, care does not arise from the benefits accruing to identity, but from the unboundedness of wholeness. This is how we understand the comments from the floodplains person cited by Rose. Returning home after being away, they comment, 'you see the birds ... you see the country, and your senses come back to you. You know what to do and where to go'. ${ }^{44}$ This suggests that this person sees, smells, feels and knows through country; that country is inside them as they are inside it. This is an experience of wholeness rather than identity.

-CONCLUSION

In conclusion, let us return to the issue of custodianship, that is, responsibility for and responsiveness to the other.

Proprietorial forms of belonging describe care for place as a care of the self. Where there is a proprietorial subject who assumes responsibility for an other, responsiveness or receptivity to the other is not possible, for, in this ontological form, the other remains an object to the subject, a separate thing, abstracted from 
living space and time. Thus, place and the creatures and beings that inhabit it are reduced to being the objects of human subjects: because this place is my place, I am responsible for its care.

Rose attempts to avoid this proprietorial logic by assigning subjecthood to places and creatures as well as humans. This allows her to conceive of belonging as mutual attention: I care for this place and this place cares for me. However, when Rose gives logical priority to distinct subjects, she is unable to conceptualise a genuine relational state. She describes a world in Euclidean and linear terms, where here and now are distinct positions, but cannot imagine genuinely ecological space and time where here is here-and-there and now is now-and-then. While she can develop a model of the ecologically emplaced self, where connections arise through interactions between locatable subjects, she cannot conceive of an ecological form of being that involves the intertwinement of person-and-place.

A custodial form of belonging, we have argued, is based on a relational ontology, an ecological form of being which is open to and part of the world of undefinable differences. Since ecological being participates in the world to which it responds, the difference that calls (-and-responds) is inside and outside, here-andthere. Responsibility does not come from anyone, and is not to anyone, but emerges from relation.

This has implications for how we think about specificity, that is, responsibility for this place. By deriving specificity through locations and boundedness, Rose inadvertently invokes a proprietorial form of belonging which excludes others. We are proposing instead a relational form of belonging that is both specific and inclusive. This was Buber's point in his discussion of the encounter with the tree. When he is 'bound up in relation' to this tree, this I-Thou encounter does not exclude locations or boundaries or identifications. More importantly, however, an I-Thou form of belonging includes others, here. Custodial belonging based on I-Thou recognises the implication and inclusion of other people and places in this place, and, conversely, 'my' implication in and responsibility for other people and places. All are here, now in this. 
The authors have worked together in the School of Social Sciences, University of New South Wales, Sydney. Ann Game and Andrew Metcalfe have written four books collaboratively: Passionate Sociology, The Mystery of Everyday Life, The First Year Experience and Teachers who Change Lives. Additionally, Ann is co-author of Gender at Work and author of Undoing the Social, and Andrew is author of For Freedom and Dignity. Demelza Marlin has written about concepts of incarnation and enchantment in narratives of secularisation. Ann, Andrew and Demelza have written a book, On Bondi Beach, which will be published in October 2013. 
'CERES: Singing up the City', PAN: Philosophy, Activism, Nature, vol. 1, 2000, pp. 5-15; Val Plumwood, 'Shadow Places and the Politics of Dwelling', Australian Humanities Review, no. 44, March 2008;

Deborah Bird Rose, 'Dialogue with Place: Toward an Ecological Body', JNT: Journal of Narrative Theory, vol. 32, no. 3, 2002, pp. 311-25; Rose, 'An Indigenous Philosophical Ecology: Situating the Human', The Australian Journal of Anthropology, vol. 16, no. 3, 2005, p. 294-305.

${ }^{15}$ Veronica Brady, “'Teach Us to Care and to Not Care”: Settling into Australia at Last', in Australia who Cares?, ed. D. Callahan, Network Books, Perth, 2007 p. 17.

${ }^{16}$ Buber, Way of Response, p. 20.

${ }^{17}$ Buber, I and Thou, p. 14, emphasis added.

${ }^{18}$ Buber, Meetings, p. 3.

${ }^{19}$ Deborah Bird Rose, 'Dialogue with Place', p. 311.

${ }^{20}$ Rose, 'An Indigenous Philosophical Ecology', p. 294.

${ }^{21}$ Ibid., p. 300.

${ }^{22}$ Ibid., p. 301

${ }^{23}$ Ibid., pp. 297-98.

${ }^{24}$ Ibid., p. 322.

${ }^{25}$ Deborah Bird Rose, 'Taking Notice', Worldviews: Environment, Culture, Religion, vol. 3, 1999, pp. 98100.

${ }^{26}$ Rose, 'An Indigenous Philosophical Ecology', p. 302.

${ }^{27}$ Deborah Bird Rose, Nourishing Terrains: Australian Aboriginal Views of Landscape and Wilderness, Australian Heritage Commission, Canberra, 1996, p. 10.

${ }^{28}$ Rose, 'An Indigenous Philosophical Ecology', p. 302

${ }^{29}$ Rose, 'Taking Notice', p. 100.

${ }^{30}$ Rose, 'Dialogue with Place', p. 320.

${ }^{31}$ Ibid., p. 322.

${ }^{32}$ Ibid., p. 319.

${ }^{33}$ Rose, 'Taking Notice', p. 99.

${ }^{34}$ Deborah Bird Rose, 'Pattern, Connection, Desire: In honour of Gregory Bateson', Australian Humanities Review, vol. 35, June 2005, p. 4.

${ }^{35}$ Ibid., pp. 4-5.

${ }^{36}$ See, for example, Deborah Bird Rose, 'Dark Times and Excluded Bodies in the Colonisation of Australia', in The Resurgence of Racism, eds Geoffrey Gray and Christine Winter, Monash Publications, Melbourne, 1997, pp. 97-116; Deborah Bird Rose, Dingo Makes Us Human, Cambridge University Press, Cambridge, 2000.

${ }^{37}$ Rose, Dingo Makes Us Human, pp. 203-4.

${ }^{38}$ Ibid., p. 203.

${ }^{39}$ Ibid., p. 213. 
40 Ibid., p. 215-16.

41 Ibid., p. 217.

${ }^{42}$ Rose, 'Taking Notice', p. 98.

${ }^{43}$ Ibid., p. 100.

${ }^{44}$ Rose, 'An Indigenous Philosophical Ecology', p. 299. 